\title{
The Complete Chloroplast Genome Sequence and Intra-Species Diversity of Rhus chinensis
}

\author{
Inseo Kim, Jee Young Park', Yun Sun Lee ${ }^{1}$, Ho Jun Joh ${ }^{1}$, Shin Jae Kang ${ }^{1}$, Jayakodi Murukarthick ${ }^{1}$, Hyun Oh Lee ${ }^{2}$, \\ Young-Jin $\mathrm{Hur}^{3}$, Yong $\mathrm{Kim}^{3}$, Kyung Hoon $\mathrm{Kim}^{3}$, Sang-Choon Lee ${ }^{1}$, Tae-Jin Yang ${ }^{{ }^{*}}$ \\ ${ }^{1}$ Department of Plant Science, Plant Genomics and Breeding Institute, and Research Institute of Agriculture and Life Sciences, \\ College of Agriculture and Life Sciences, Seoul National University, Seoul 08826, Korea \\ ${ }^{2}$ Phyzen Genomics Institute, Seongnam 13558, Korea \\ ${ }^{3}$ Il Song ERT. Co. LTD, Yongin 16950, Korea
}

\begin{abstract}
Rhus chinensis is a shrub widely distributed in Asia. It has been used for traditional medicine and ecological restoration. Here, we report the complete chloroplast genome sequence of two R. chinensis genotypes collected from China and Korea. The assembled chloroplast genome of Chinese $R$. chinensis is 149,094 bp long, consisting of a large single copy ( $97,246 \mathrm{bp}$ ), a small single copy $(18,644 \mathrm{bp})$ and a pair of inverted repeats $(16,602 \mathrm{bp})$. Gene annotation revealed 77 protein coding genes, 30 tRNA genes, and 4 rRNA genes. A phylogenomic analysis of the chloroplast genomes with 11 known complete chloroplast genomes clarified the relationship of $R$. chinensis with the other plant species in the Sapindales order. A comparative chloroplast genome analysis identified 170 SNPs and 85 InDels at intra-species level of $R$. chinensis between Chinese and Korean collections. Based on the sequence diversity between Korea and Chinese $R$. chinensis plants, we developed three DNA markers useful for genetic diversity and authentication system. The chloroplast genome information obtained in this study will contribute to enriching genetic resources and conservation of endemic Rhus species.
\end{abstract}

Keywords Rhus chinensis, Medicinal plant, Ecological restoration, DMZ, Chloroplast genome sequence, Molecular marker

\section{INTRODUCTION}

Rhus chinensis is a deciduous shrub belonging to the family Anacardiaceae and distributed widely in Asia including India, Vietnam, China, Korea, and Japan (Min and Barfod 2008). It contains various pharmacologically active constituents and insect-induced galls, which have been used for medicinal purposes (Min and Barfod 2008; Djakpo and Yao 2010). In addition, $R$. chinensis is used as revegetation plant for ecological restoration owing to its cold tolerance and easy multiplication by both seed and clonal propagation (Nam et al. 2004; Lim and Oh 2015). The diverse utilization of this shrub led to international seed trading which in turn resulted in contamination and destruction of endemic population of $R$. chinensis. Although the generic and infrageneric delimitation of Rhus species remains controversial, very limited genetic resources are available for R. chinensis (Young 1978; Miller et al. 2001; Yi et al. 2004; Ma et al. 2013; Lee et al. 2016). In this study, we have characterized the complete chloroplast genome of Chinese $R$. chinensis and compared with Korean $R$. chinensis chloroplast genome for estimating genetic diversity and developing marker for authentication.

Chloroplast DNA has a characteristic of exhibiting variations at intra-species level and thus chloroplast DNA has widely been used for classification among populations.

Received August 19, 2017; Revised August 19, 2017; Accepted August 19, 2017; Published September 1, 2017

*Corresponding author Sang-Choon Lee, sclee0923@snu.ac.kr, Tel: +82-2-880-4557, Fax: +82-2-873-2056

Tae-Jin Yang, tjyang@snu.ac.kr, Tel: +82-2-880-4547, Fax: +82-2-873-2056 
Chloroplast genomes are uni-parentally inherited and contain rare recombination and mutation events (Cheng et al. 2005; Dong et al. 2012). These features make chloroplast genomes good candidate for studying evolution at inter- or intra-species level. For instance, intra-species researches had been conducted using chloroplast DNA in various plant species including Panax ginseng, Pedicularis chamissonis, Primula cuneifolia, Tellima grandiflora, and Tiarella trifoliata (Soltis et al. 1991; Soltis et al. 1992; Fujii et al. 1995; Sewell et al. 1996; Fujii et al. 1997; Kim et al. 2015a; Joh et al. 2017). Chloroplast genome was also applied to taxonomic studies of Rhus and marker development to classify species (Miller et al. 2001; Lee et al. 2004; Yi et al. 2004; Yi et al. 2007). However, high resolution markers have not been developed for distinguishing Rhus species at both inter- and intra-species level.

In this study, we assembled the complete chloroplast genome of two R. chinensis genotypes from China and Korea. In addition, we have conducted a comparative phylogenomic analysis of Chinese and Korean $R$. chinensis along with 11 species belonged in the Sapindales order. We also developed polymorphic DNA markers derived from chloroplast genomes to practically apply for authentication and genetic diversity among $R$. chinensis collections.

\section{MATERIALS AND METHODS}

\section{Plant materials and genome sequencing}

Seeds of wild Chinese $R$. chinensis were obtained from Shandong and Henan provinces in China. We also collected seven $R$. chinensis samples in Korea (Table 1): two samples from demilitarized zone (DMZ) between South and North Korea and five samples from other locations in South Korea. We sequenced plants collected from Yang-gu province in Korea and Shandong and Henan provinces in China as representatives of the collections of Korea and China. The genomic DNAs were extracted from the leaf tissues or seeds of collected plants using a modified cetyltrimethylammonium bromide (CTAB) method (Allen et al. 2006) and quantified using Nanodrop ND-1000 (Nanodrop Technologies, Inc., Wilmington, DE, USA). Paired-end (PE) sequencing was conducted using Illumina MiSeq platform by LabGenomics (www.labgenomics.co.kr, Seongnam, Korea).

\section{Chloroplast genome assembly}

Raw PE reads were trimmed and de novo assembled using the method as described by Kim et al. (2015a, 2015b). From initial assembly, contigs representing chloroplast genome sequences were extracted, ordered, and merged to generate a single contig sequence using the reference chloroplast genome Acer buergerianum ssp. ningpoense (KF753631, Yang et al. 2014). The assembled sequence was manually corrected and gap-filled by a series of PE read mapping. The assembled chloroplast genome was annotated using GeSeq (https://chlorobox.mpimp-golm.mpg.de/geseq-app.html) and manually curated using the Artemis annotation tool (Rutherford et al. 2000).

\section{Phylogenetic analysis}

Phylogenetic analysis was carried out using multiple sequence alignments of 13 complete chloroplast genome

Table 1. Sample collections of $R$. chinensis used in this study.

\begin{tabular}{|c|c|c|c|}
\hline $\begin{array}{l}\text { Accession } \\
\text { nos. }\end{array}$ & Countries & Collected locations & $\begin{array}{c}\text { Collected } \\
\text { year }\end{array}$ \\
\hline 1 & China & Shandong and Henan provinces & 2014 \\
\hline 2 & Korea & Yang-gu, Gangwon-do & 2014 \\
\hline 3 & Korea & Hwacheon, Gangwon-do & 2014 \\
\hline 4 & Korea & Mt.Jiri, Sancheong, Kyungsangnam-do, & 2014 \\
\hline 5 & Korea & Han-taek Botanical Garden, Yong-in, Kyungki-do & 2015 \\
\hline 6 & Korea & Mt. Kariwang, Jeong-seon, Gangwon-do & 2015 \\
\hline 7 & Korea & Gwangreung Botanical Garden, Korea National Arboretum, Po-cheon, Gyeonggi-do & 2015 \\
\hline 8 & Korea & Gwangreung Botanical Garden, Korea National Arboretum, Po-cheon, Gyeonggi-do & 2015 \\
\hline
\end{tabular}


sequences (Acer burgerianum ssp. ningpoense, KF753631; Acer davidii, NC_030331; Acer miaotaiense, NC_030343; Azadirachta indica, NC_023792; Boswellia sacra, KT934315; Citrus aurantiifolia, KJ865401; Citrus sinensis, DQ864733; Dipteronia sinensis, NC_029338; R. chinensis (China), MF351625; R. chinensis (Korea), NC_033535; Sapindus mukorossi, KM454982; Spondias bahiensis, KU756561; Spondias tuberosa, KU756562) that belong to the Sapindales order. Phylogenetic tree was constructed using MEGA6.0 (Tamura et al. 2013) with the parameters of neighbor-joining method and 1000 bootstrap replicates.

\section{Comparison of intra-species level and development of molecular marker}

Sequence variations were identified by mVISTA program (http://genome.lbl.gov/vista/mvista/submit.shtml) and the polymorphic sites were arranged by MAFFT program (http://mafft.cbrc.jp/alignment/software). The two types of molecular markers, InDel and SNP, were developed based on the polymorphic sites in chloroplast genomes of two $R$. chinensis. The primers were designed using Primer-blast tool in NCBI (https://www.ncbi. nlm.nih.gov/tools/primer-blast/). PCR reactions were performed in $25 \mu \mathrm{L}$ final volume which is composed of 20 ng of template DNA, 1x Taq buffer, 2.5 mM dNTP, 10 pmol of each primer, and 2 unit/ $\mu \mathrm{L}$ Taq DNA polymerase (Vivagen, Korea). PCR conditions were as follows: 5 minutes at $95^{\circ} \mathrm{C}, 35$ cycles of 30 seconds at $95^{\circ} \mathrm{C}, 30$ seconds at $56^{\circ} \mathrm{C}$, and 30 seconds at $72^{\circ} \mathrm{C}$, and 5 minutes at $72^{\circ} \mathrm{C}$ as final extension. PCR amplicons were inspected using $3 \%$ agarose gel including Inclone ${ }^{\mathrm{TM}}$ Safe Gel stain. Then they were visualized under UV trans-illuminator and a gel documentation system.

PCR reaction for high resolution melting (HRM) analysis against SNP target was performed in a $20 \mu \mathrm{L}$ final volume which consists of $20 \mathrm{ng}$ of template DNA, 1x Taq buffer, $2.5 \mathrm{mM}$ dNTP, 10 pmol of each primer, 2 unit $/ \mu \mathrm{L}$ Taq DNA polymerase (Vivagen, Korea), and fluorescent dye SYTO 9 (Roche Diagnostics). PCR conditions were as follows: 5 minutes at $95^{\circ} \mathrm{C}, 45$ cycles of 30 seconds at $95^{\circ} \mathrm{C}, 30$ seconds at $56^{\circ} \mathrm{C}$, and 30 seconds at $72^{\circ} \mathrm{C}$, and 5 minutes at $72^{\circ} \mathrm{C}$ as final extension. Then, HRM analysis was conducted using LightCycler 480 (Roche Applied
Science). HRM conditions were as follows: 1 minute at $95^{\circ} \mathrm{C}, 1$ minute at $40^{\circ} \mathrm{C}, 5$ seconds at $70^{\circ} \mathrm{C}$, and the temperature increased up to $90^{\circ} \mathrm{C}$, then decreased to $40^{\circ} \mathrm{C}$ as fluorescence acquisition.

\section{RESULTS}

\section{Complete chloroplast genome and intra-species polymorphism between Korean and Chinese R. chinensis}

The assembled chloroplast genome of Chinese $R$. chinensis is a circular molecule of 149,094 bp long and has typical quadripartite structure consisting of a large single copy (LSC) region of 97,246 bp small single copy (SSC) region of 18,644 bp and a pair of inverted repeats (IRa and $\mathrm{IRb}$ ) of 16,602 bp (Fig. 1, Table 2). A total of 111 genes, including 77 protein coding genes, 30 tRNA genes, and 4 rRNA genes were annotated (Table 3 ) and the GC content of the chloroplast genome was $37.86 \%$.

Comparison of the chloroplast genome of Korean and Chinese $R$. chinensis revealed a total length $83 \mathrm{bp}$ differences. Chinese $R$. chinensis is 364 bp longer than Korean $R$. chinensis in LSC region, but 139 bp and $3 \mathrm{bp}$ shorter in IR and SSC regions, respectively. We identified 170 SNPs and 85 InDels between two $R$. chinensis chloroplast genome sequences derived from Chinese and Korean collections (NC_033535, Lee et al. 2016). More intra-species polymorphic sites were found at intergenic regions than genic regions: 99 SNPs and 78 InDels were found at intergenic regions; 71 SNPs and 7 InDels were identified from genic regions.

\section{Phylogenomic analysis of $R$. chinensis based on chloroplast genome}

Phylogenomic analysis was conducted using two complete chloroplast genomes $R$. chinensis and 11 complete chloroplast genome sequences in the Sapindales order. This results showed, as expected, that $R$. chinensis was grouped with Spondias species in the Anacardiaceae family (Fig. 2). In addition, a group including $R$. chinensis showed a close sister relationship with species belonging to the Burseraceae and Sapindaceae family in the Sapindales order. 


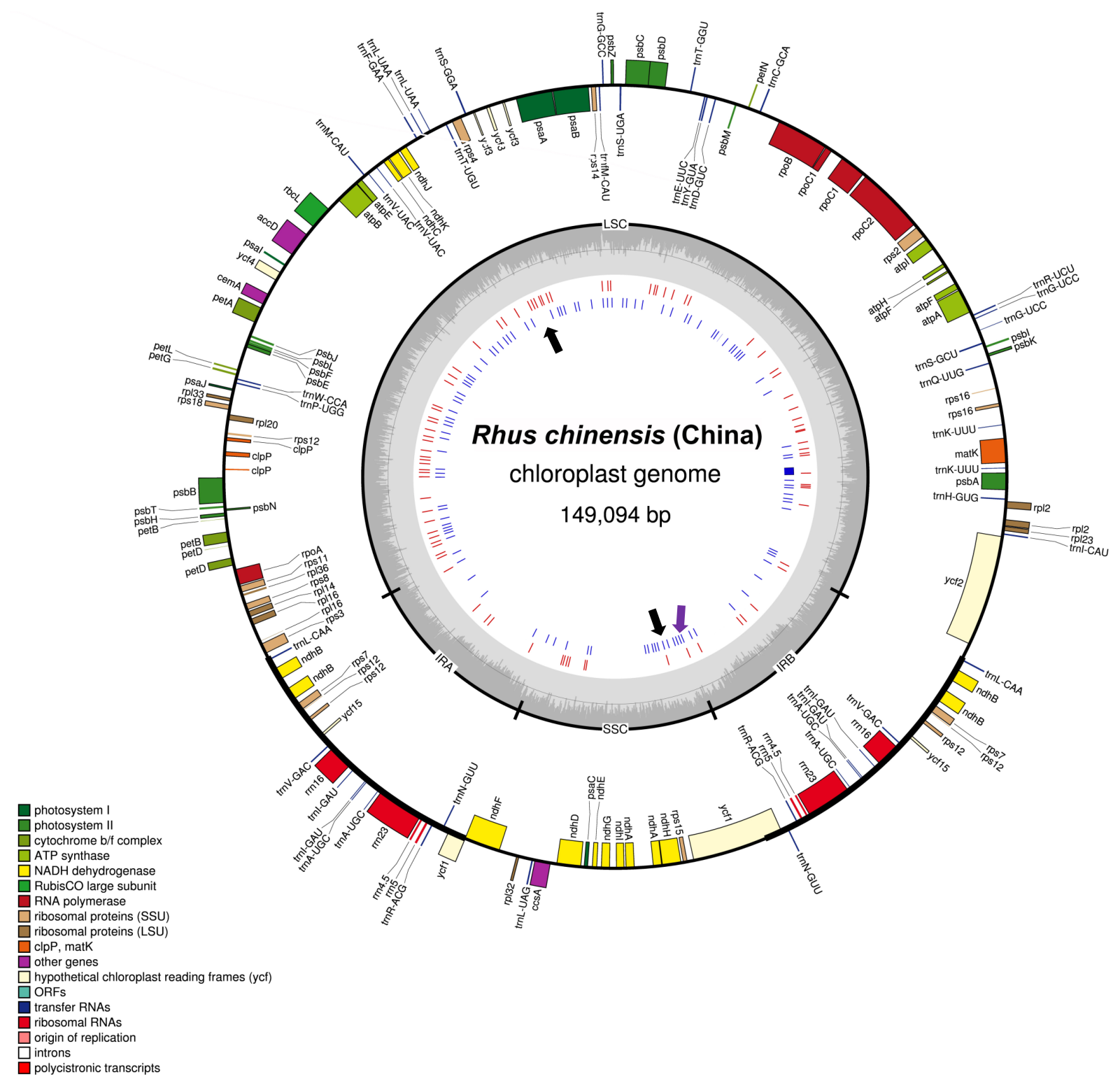

Fig. 1. Chloroplast genome map of $R$. chinensis and intra-species polymorphic DNA markers. (a) Chloroplast genome map of $R$. chinensis generated using OGDRAW (http://ogdraw.mpimp-golm.mpg.de/). Genes transcribed clockwise and counterclockwise are indicated on the outside and inside of the large circle, respectively. The four parts of the chloroplast genome and GC content are indicated on the inner circle. Red and blue bars in the inner circle indicate intra-species InDels and SNPs identified between Chinese and Korean R. chinensis chloroplast genome sequences. Black arrows represent the target regions for InDel markers and the purple arrow indicates SNP used to differentiate between Chinese and Korean R. chinensis.

Table 2. Summary of NGS data and chloroplast genomes of two Rhus chinensis collections.

\begin{tabular}{|c|c|c|c|c|c|c|}
\hline Collected locations & $\begin{array}{l}\text { Raw data } \\
\text { bases (bp) }\end{array}$ & $\begin{array}{l}\text { Cp genome } \\
\text { coverage }(x)\end{array}$ & $\begin{array}{l}\text { Cp length } \\
\text { (bp) }\end{array}$ & $\begin{array}{l}\text { LSC length } \\
\text { (bp) }\end{array}$ & $\begin{array}{l}\text { IR length } \\
\text { (bp) }\end{array}$ & $\begin{array}{l}\text { SSC length } \\
\text { (bp) }\end{array}$ \\
\hline China & $4,199,252,923$ & 162 & 149,094 & 97,246 & 16,602 & 18,644 \\
\hline Korea (Yang-gu) $)^{z}$ & $6,251,344,649$ & 96 & 149,011 & 96,882 & 16,741 & 18,647 \\
\hline
\end{tabular}

${ }^{\mathrm{z})}$ reported by Lee et al. (2016). 
Table 3. Genes annotated in $R$. chinensis chloroplast genome.

\begin{tabular}{ll}
\hline \multicolumn{1}{c}{ Gene types } & \multicolumn{1}{c}{ Gene names } \\
\hline Photosystem I & $p s a A, B, C, I, J$ \\
Photosystem II & $p s b A, B, C, D, E, F, H, I, J, K, L, M, N, T, Z$ \\
Cytochrome b/f complex & $p e t A, B, D, G, N, L$ \\
ATP synthase & $a t p A, B, E, F, H, I$ \\
NADH dehydrogenase & $n d h A, B, C, D, E, F, G, H, I, J, K$ \\
RubisCO large subunit & $r b c L$ \\
RNA polymerase & $r p o A, B, C 1, C 2$ \\
Ribosomal proteins (SSU) & $r p s 2,3,4,7,8,11,12,14,15,16,18$ \\
Ribosomal proteins (LSU) & $r p l 2,14,16,20,23,32,33,36$ \\
clpP, matK & $c l p P, m a t K$ \\
Other genes & $c c s A, c e m A, a c c D$ \\
Hypothetical chloroplast reading frames & $y c f 1,2,3,4,15$ \\
& $t r n f M-C A U, A-U G C, C-G C A, D-G U C, E-U U C, \quad F-G A A, \quad G-G C C, U C C$, \\
Transfer RNAs & $H-G U C, I-C A U, G A U, K-U U U, L-C A A, C A U, U A G, U A A, M-C A U, N-G U U$, \\
& $P-U G G, Q-U U G, R-U C U, A C G, S-U G A, G C U, G G A, T-G G U, V-G A C, U A C$, \\
Ribosomal RNAs & $W-C C A, Y-G U A$ \\
& $r r n 4.5,5,16,23$
\end{tabular}

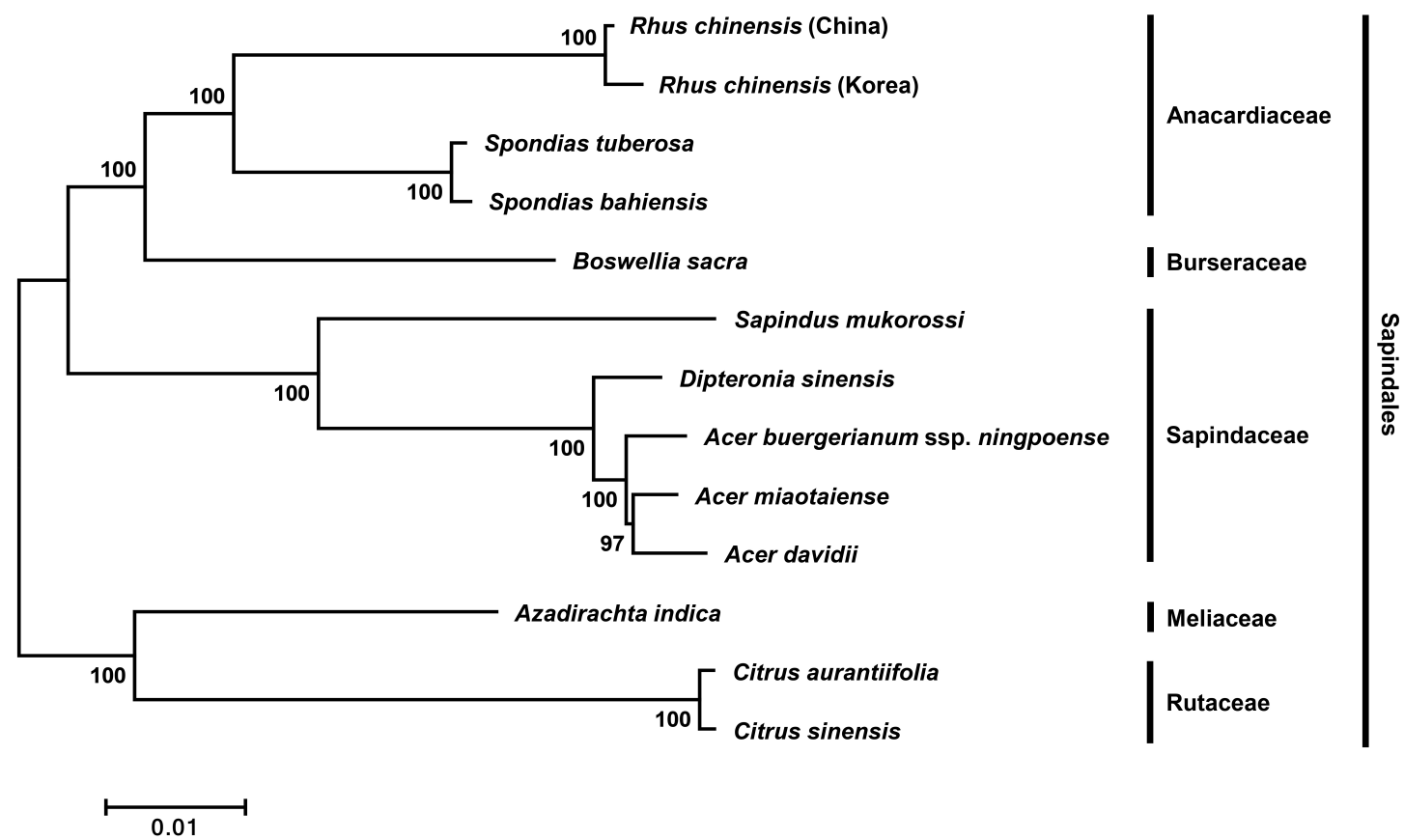

Fig. 2. Phylogenetic analysis of $R$. chinensis. The tree was generated with complete chloroplast genome sequences of $R$. chinensis and species belonging to the Sapindales order by multiple alignment using MAFFT (http://mafft.cbrc.jp/alignment/server/index.html) and a maximum likelihood (ML) analysis using MEGA 6.0 (Tamura et al. 2013). Numbers in the nodes are bootstrap support values ( $>50 \%)$ from 1000 replicates. Chloroplast genome sequences used for this tree are: Acer burgerianum ssp. ningpoense, KF753631; Acer davidii, NC_030331; Acer miaotaiense, NC_030343; Azadirachta indica, NC_023792; Boswellia sacra, KT934315; Citrus aurantiifolia, KJ865401; Citrus sinensis, DQ864733; Dipteronia sinensis, NC_029338; R. chinensis (China), MF351625; R. chinensis (Korea), NC_033535; Sapindus mukorossi, KM454982; Spondias bahiensis, KU756561; Spondias tuberosa, KU756562. 


\section{Molecular markers to discriminate Korean and Chinese collections of $R$. chinensis species}

Three intra-species polymorphic markers were designed from polymorphic regions (Table 4). The PCR amplicons showed 288/249 bp and 221/196 bp difference (Chinese/ Korean) for two InDel markers, rh_InDel_02 and rh_InDel_03 markers, respectively. The rh_InDel_02 and rh_InDel_03 showed InDel polymorphism between Korean $R$. chinensis (Yang-gu) and Chinese collection as expected (Fig. 3a, b). However other six Korean collections were identical with Chinese collections (Fig. 3c, d). One SNP marker (rh_hrm_11) distinguished Chinese collection from all the Korean collections based on HRM analysis although the size of PCR amplicons are same (Fig. 4).

\section{DISCUSSION}

\section{Intra-species diversity of $\boldsymbol{R}$. chinensis}

R. chinensis is known as a valuable medicinal plants with remedial components (Min and Barfod 2008; Djakpo and Yao 2010). In addition, $R$. chinensis is used for ecological restoration (Nam et al. 2004; Lim and Oh 2015). Due to its wide utility, it is necessary to explore this plant for genetic diversity and marker development to prevent false trading

Table 4. Molecular markers developed in this study.

\begin{tabular}{cclllcc}
\hline \hline Type & Marker Name & Target Region & & Primer Sequence & Variation & $\begin{array}{c}\text { Product } \\
\text { Size }(\mathrm{bp})\end{array}$ \\
\hline InDel & rh_InDel_02 & \multirow{2}{*}{ trnS-GGA-rps4 } & F & AGTGGTTCAAGGCGTAGCAT & 39 bp & $288 / 249$ \\
& & & R & ATTTGATCCGGCGATTTGGA & & \\
& rh_InDel_03 & $y c f 1$ & F & TGATTCGCTCGATTTCGCCA & 25 bp & $221 / 196$ \\
& & & R & TCTGTCCTTCAATATCACGGAAC & & \\
SNP & rh_hrm_11 & \multirow{2}{*}{$y c f 1$} & F & CATGTGTGCATCTCTGGGTT & G/T & 191 \\
& & & R & CTTCCTTTGGTCCAATTCTCGAT & & \\
\hline
\end{tabular}

(a)

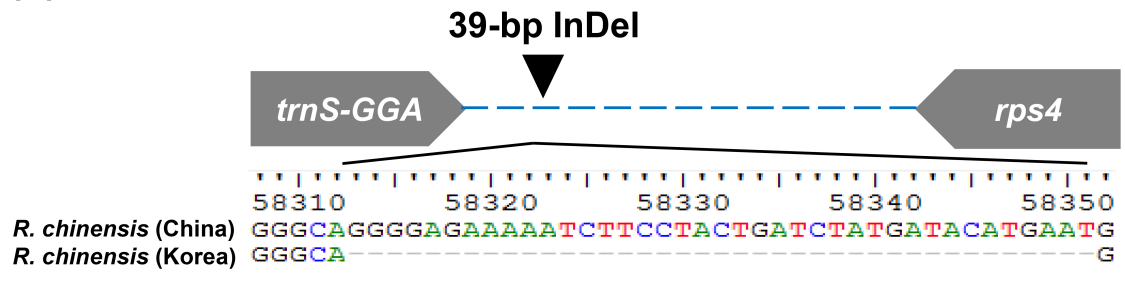

(b)

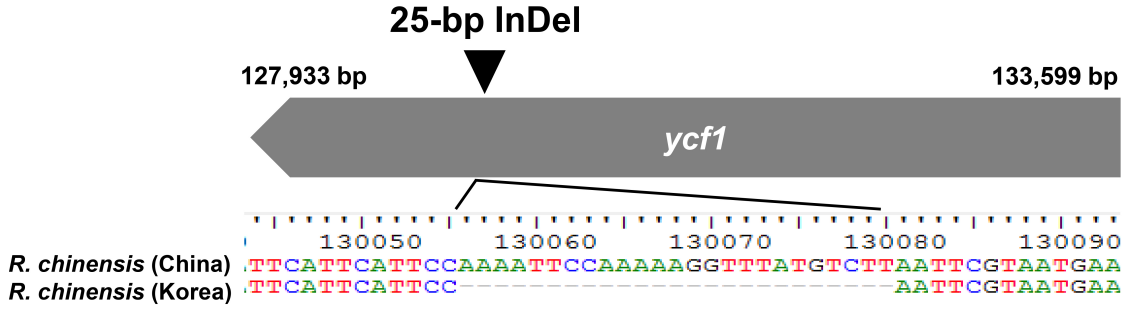

(c)

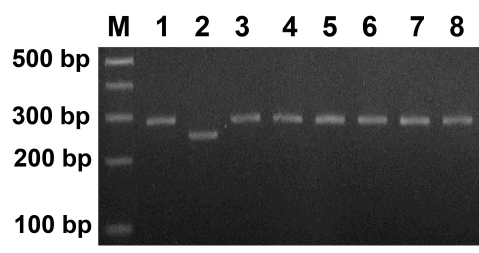

(d)

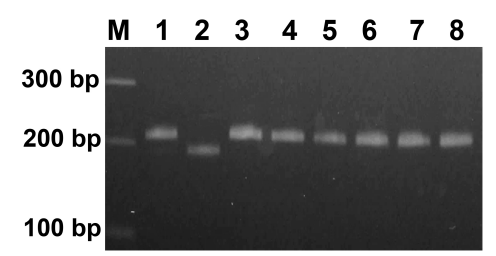

Fig. 3. Two InDel-based markers to validate intra-species diversity in $R$. chinensis. (a) A 39-bp InDel in trnS-GGA-rps4 and (c) its PCR products (Marker rh_InDel_02 in Table 4) for eight $R$. chinensis plants. (b) 25-bp InDel in $y c f 1$ and (d) its PCR products (Marker rh_InDel_03 in Table 4) for eight $R$. chinensis plants. $R$. chinensis collections 1: China (Shandong and Henan), 2: Korea (Yang-gu), 3: Korea (Hwacheon), 4: Korea (Mt. Jiri), 5: Korea (Han-taek Botanical Garden), 6: Korea (Mt. Kariwang), 7, 8: Korea (Gwangreung Botanical Garden), M: 100-bp DNA ladder. 


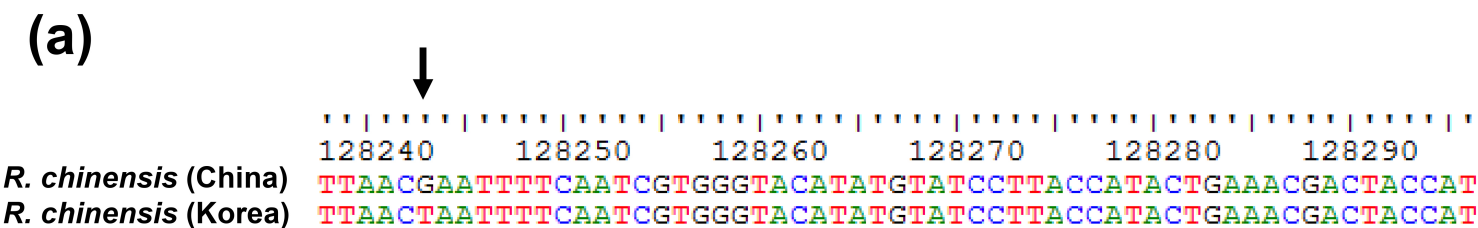

(b)

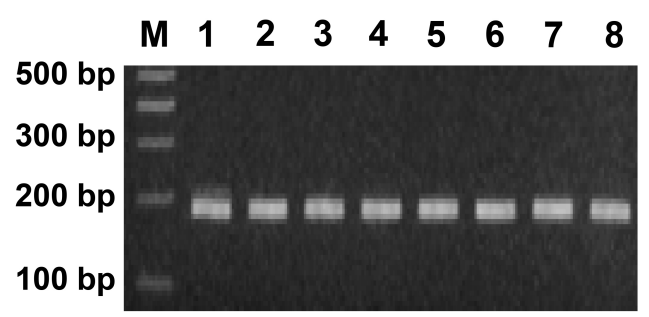

(c)

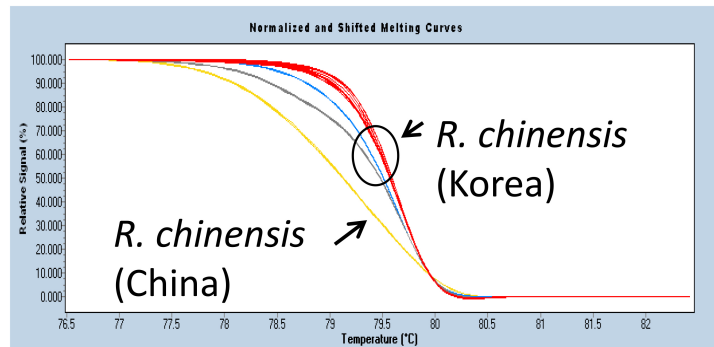

Fig. 4. SNP-based marker to validate intra-species diversity in R. chinensis. (a) Alignment of nucleotide sequences to show the SNP (arrow) in $y c f l$ gene of chloroplast of Korean and Chinese $R$. chinensis plants. (b) Agarose gel electrophoresis of the PCR products amplified by Marker rh_hrm_11 (Table 4). (c) HRM analysis of the PCR products to detect the SNP. R. chinensis collections 1: China (Shandong and Henan), 2: Korea (Yang-gu), 3: Korea (Hwacheon), 4: Korea (Mt. Jiri), 5: Korea (Han-taek Botanical Garden), 6: Korea (Mt. Kariwang), 7, 8: Korea (Gwangreung Botanical Garden), M: 100-bp DNA ladder.

(Khairallh and Salama 2009). Here, we generated the complete chloroplast genome of two $R$. chinensis plants collected from Korea and China. Comparative analysis of chloroplast genome of $R$. chinensis revealed 255 intraspecies polymorphic sites, 170 SNPs and 85 InDels. The abundant genetic diversity would be found in the wild collections of $R$. chinensis and could be applied to phylogenetic analysis and development of molecular markers for verifying genetic diversity of $R$. chinensis.

\section{Discrimination of $\boldsymbol{R}$. chinensis collections with three molecular markers}

Two InDel markers were unique for one Korean collection of $R$. chinensis (Yang-gu) from the others (Fig. $3 \mathrm{a}, \mathrm{b})$. The Yang-gu collection is derived from the DMZ region between South Korea and North Korea. The eco-system was well maintained in DMZ regions for longer than 60 recent years with less artificial interruption. Two InDel markers revealed unique genotype of Yang-gu collection among the eight collections, suggesting the Yang-gu collection are relatively isolated in the DMZ region from others. However, it is required to expand our study by evaluating more population for solid conclusion. Meanwhile, the SNP markers could efficiently divide the melting patterns for Chinese $R$. chinensis from Korean $R$. chinensis through HRM analysis (Fig. 4).

Chloroplast genomes are valuable genomic resources for practical application of DNA markers because of the uni-parentally inherited features and conserved structure of the chloroplast genomes (Cheng et al. 2005; Dong et al. 2012, Kim et al. 2015a, 2015b, 2015c; Joh et al. 2017). Here, we report three DNA markers which can be applied for genetic diversity and practical application for authentication of the plant collections of Rhus species.

\section{ACKNOWLEDGEMENTS}

This work was supported by the Korea Environmental Industry \& Technology Institute (Project No.: 2014000130001) and the Bio \& Medical Technology Development Program of the NRF funded by the Korean government, MSIP 
(NRF-2015M3A9A5030733).

\section{REFERENCES}

Allen GC, Flores-Vergara MA, Krasynanski S, Kumar S, Thompson WF. 2006. A modified protocol for rapid DNA isolation from plant tissues using cetyltrimethylammonium bromide. Nat. Protoc. 1: 2320-2325.

Cheng Y, de Vicente MC, Meng H, Guo W, Tao N, Deng X. 2005. A set of primers for analyzing chloroplast DNA diversity in Citrus and related genera. Tree Physiol. 25: 661-672.

Djakpo O, Yao W. 2010. Rhus chinensis and Galla Chinensis--folklore to modern evidence: review. Phytother. Res. 24: 1739-1747.

Dong W, Liu J, Yu J, Wang L, Zhou S. 2012. Highly variable chloroplast markers for evaluating plant phylogeny at low taxonomic levels and for DNA barcoding. PLoS One 7: e35071.

Fujii N, Ueda K, Watano Y, Shimizu T. 1995. Intraspecific sequence variation in chloroplast DNA of Primula cuneifolia Ledeb. (Primulaceae). J. Phytogeogr. Taxon. 43: 15-24.

Fujii N, Ueda K, Watano Y, Shimizu T. 1997. Intraspecific sequence variation of chloroplast DNA in Pedicularis chamissonis Steven (Scrophulariaceae) and geographic structuring of the Japanese "Alpine" plants. Journal of Plant Research 110: 195-207.

Joh HJ, Kim NH, Jayakodi M, Jang WJ, Park JY, Kim YC, et al. 2017. Authentication of golden-berry $P$. ginseng cultivar 'Gumpoong' from a landrace 'Hwangsook' based on pooling method using chloroplast-derived markers. Plant Breed. Biotech. 5: 16-24.

Khairallh ARAT, Salama B. 2009. Genetic variation among sumac (Rhus Coriaria L.) samples collected from three locations in Jordan as revealed by AFLP markers. Advances in Environmental Biology 3: 107-112.

Kim K, Lee SC, Lee J, Lee HO, Joh HJ, Kim NH, et al. 2015a. Comprehensive survey of genetic diversity in chloroplast genomes and $45 \mathrm{~S}$ nrDNAs within Panax ginseng species. PLoS One 10: e0117159.

Kim K, Lee SC, Lee J, Yu Y, Yang K, Choi BS, et al. 2015b. Complete chloroplast and ribosomal sequences for 30 accessions elucidate evolution of Oryza AA genome species. Sci Rep 5: 15655.

Kim KH, Kim YS, Kim MR, Lee HY, Lee KH, Kim JH, et al. 2015c. Development of primer sets for the detection of Polygonum multiflorum, Cynanchum wilfordii and $C$. auriculatum. Journal of Food Hygiene and Safety 30: 289-294.

Lee YS, Kim IS, Kim JK, Park JY, Joh HJ, Park HS, et al. 2016. The complete chloroplast genome sequence of Rhus chinensis Mill (Anacardiaceae). Mitochondrial DNA Part B 1: 696-697.

Lee WK, Kim MJ, Heo K. 2004. Phylogeny of Korean Rhus spp. based on ITS and $r b c L$ sequences. Korean Journal of Medicinal Crop Science 12: 60-66.

Lim CY, Oh CH. 2015. Growth and spatial distribution characteristics of Rhus javanica populations sowed on cut-slopes. J. Korean Env. Res. Tech. 18: 39-49.

Ma WL, Wu M, Wu Y, Ren ZM, Zhong Y. 2013. Cloning and characterisation of a phenylalanine ammonia-lyase gene from Rhus chinensis. Plant Cell Rep. 32: 1179-1190.

Miller AJ, Young DA, Wen J. 2001. Phylogeny and biogeography of Rhus (Anacardiaceae) based on ITS sequences data. Int. J. Plant Sci. 162: 1401-1407.

Min T, Barfod A. 2008. Anacardiaceae (http://www.efloras. org/florataxon.aspx?flora id=2\&taxon id=10038). In: ZY. $\mathrm{Wu}, \mathrm{PH}$. Raven, DY. Hong (eds). Flora of China. Vol. 11. Science Press and Missouri Botanical Garden Press, Beijing, China and St. Louis, Missouri, (MO), USA.

Nam SJ, Yeo WJ, Choi JH, Kim NC. 2004. Development of revegetation method using forest topsoils for ecological restoration of the slopes (I). J. of Korean Env. Res. \& Reveg. Tech. 7: 110-119.

Rutherford K, Parkhill J, Crook J, Horsnell T, Rice P, Rajandream MA, et al. 2000. Artemis: sequence visualization and annotation. Bioinformatics 16: 944-945.

Sewell MM, Parks CR, Chase MW. 1996. Intraspecific chloroplast DNA variation and biogeography of North American Liriodendron L. (Magnoliaceae). Evolution 50: $1147-1154$

Soltis D, Soltis P, Kuzoff R, Tucker T. 1992. Geographic structuring of chloroplast DNA genotypes in Tiarella trifoliata (Saxifragaceae). Plant Systematics and Evolution 181: 203-216.

Soltis DE, Mayer MS, Soltis PS, Edgerton M. 1991. Chloroplast-DNA variation in Tellima grandiflora (Saxifragaceae). American Journal of Botany 78: 1379-1390. 
Tamura K, Stecher G, Peterson D, Filipski A, Kumar S. 2013. MEGA6: molecular evolutionary genetics analysis version 6.0. Mol. Biol. Evol. 30: 2725-2729.

Yang JB, Li DZ, Li HT. 2014. Highly effective sequencing whole chloroplast genomes of angiosperms by nine novel universal primer pairs. Mol. Ecol. Resour. 14: 1024-1031.

Yi T, Miller AJ, Wen J. 2004. Phylogenetic and biogeographic diversification of Rhus (Anacardiaceae) in the Northern Hemisphere. Mol. Phylogenet. Evol. 33:
861-879.

Yi T, Miller AJ, Wen J. 2007. Phylogeny of Rhus (Anacardiaceae) based on sequences of nuclear Nia-i3 intron and chloroplast trnC-trnD. Systematic Botany 32: 379-391.

Young DA. 1978. Re-evaluation of the section of Rhus L. subgenus Lobadium (Raf.) T. and G. (Anacardiaceae). Brittonia 30: 411-415. 